\title{
Consommation de ressources ligneuses dans un taillis de chênes par des brebis en estive
}

\author{
E Lecrivain, B Leclerc, A Hauwuy
}

INRA-SAD, Unité d'Écodéveloppement, 84140 Montfavet, France

\begin{abstract}
Summary - In a coppice, under conditions of low grass availability and high stocking rate (300 ewes $\mathrm{ha}^{-1}$ ), the time spent eating bushes reaches $60 \%$ of grazing time and increases with flock size (stocking rates of 50 ewes $\cdot h a^{-1}$ vs 150 ewes ha $^{-1}$ ).
\end{abstract}

Introduction - L'étude vise à mettre en évidence l'aptitude des brebis à consom. mer des végétaux ligneux durant l'été, dans un parcours boisé des Alpes de Haute Provence et à comparer leur comportement alimentaire dans deux situations très différentes de chargement instantané.

Matériel et Méthodes - Deux troupeaux, l'un de 50 ( $T 50$ ), l'autre de 150 (T150) brebis taries de race Préalpes, sont placés dans des parcs d'un hectare à végétation similaire, pendant $6 \mathrm{j}$ pour le premier et $2 \mathrm{j}$ pour le second. La charge cumulée est identique ( 300 brebis $h a^{-1}$ ). Les deux troupeaux pâturent successivement dans 4 formations végétales qui se caractérisent par un couvert arboré et arbustif abondant à Quercus pubescens, Pinus nigra, Genista cinerea, Amelanchier ovalis, et un tapis herbacé à Aphyllantes monspeliensis, Bromus erectus, Brachypodium pinnatum et Brachypodium phoenicoides peu abondant ( $\leq 400 \mathrm{~kg}$ de MS). Les formations $A$ et $D$ sont très arborées alors que les formations $B$ et $C$ sont plus arbustives. L'expérimentation est renouvelée en juin ou juillet, 3 années consécutives pour les formations $A$ et $B$ et 2 années consécutives pour les formations $C$ et $D$ ( 10 comparaisons au total).

Par sondage instantané dans le troupeau, un observateur note successivement pour une trentaine d'animaux le nom de la plante qu'ils prélèvent. Les observations ont lieu du lever du jour à la tombée de la nuit, à intervalle d'une demi-heure. Le nombre de jours de suivi par parc a varié, selon les années, entre 1 et 3 pour le T50 et entre 1 et 2 pour le T150. Les résultats sont exprimés en pourcentage du temps de pâturage passé à prélever les végétaux ligneux. A cause de l'évolution rapide des disponibilités alimentaires des parcs, ils sont rapportés à des chargements cumulés.

Résultats et Discussion - Sur un total de 33 journées d'observation, la part du temps consacrée à la consommation de ligneux dépasse $30 \%$ dans les deux tiers des cas et atteint $60 \%$ dans 6 cas (fig 1). Une proportion de temps aussi importante consacrée à prélever des espèces ligneuses, ressemble à un comportement de caprins pâturant des milieux boisés. Par ailleurs, dans 9 des 10 comparaisons, les ligneux sont plus consommés par le troupeau à forte charge instantanée que par le troupeau à plus faible charge, ceci indépendamment de l'année ou de la formation végétale. La taille respective des deux troupeaux nous parait induire ces différences. En effet, comme les brebis sont très grégaires, la disponibilité en herbe dans l'entourage immédiat de chaque animal est plus faible, et la compétition pour cette herbe d'autant plus forte que le troupeau est important: ceci se traduit par un report plus conséquent sur les ligneux. 

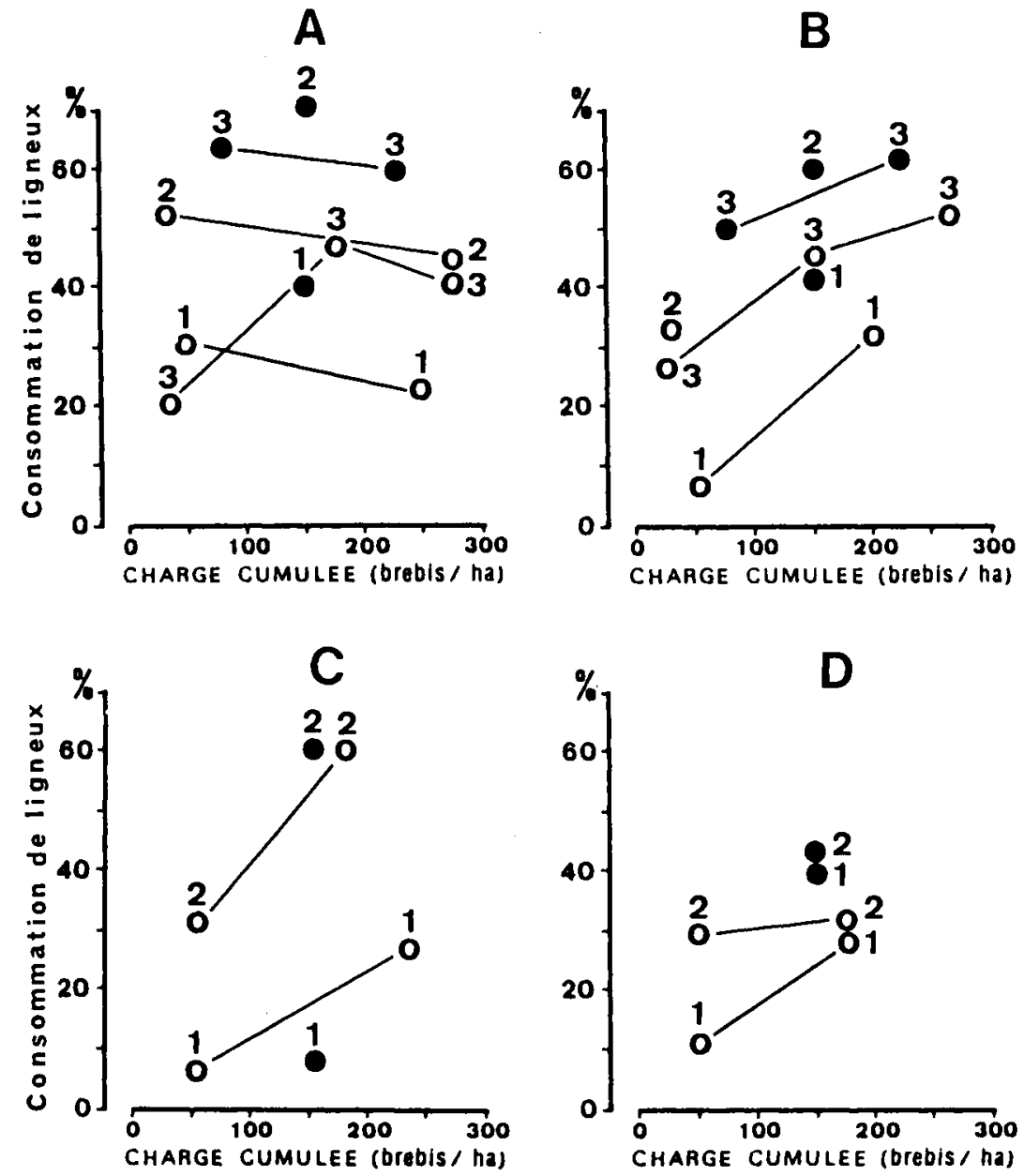

Fig 1. Comparaison de la consommation de végétaux ligneux par deux troupeaux (T50 et T150) dans 4 formations végétales ( $A, B, C$ et $D$ ). La consommation est exprimée en pourcentage du temps total de pâturage passé à prélever des ligneux. Chaque donnée étant une moyenne journalière, elle est positionnée à mi-distance entre la charge cumulée en début de journée et celle obtenue en fin de journée. O: T50; ๑: T150, 1: $1^{\theta}$ année; 2: $2^{\theta}$ année; 3: $3^{\theta}$ année.

En conclusion, dans un milieu pauvre en espèces herbacées, des brebis taries conduites en forte charge sont capables d'orienter leurs choix alimentaires vers des espèces ligneuses. Cependant, à charge cumulée équivalente (nombre de jours $x$ nombre d'animaux), le temps passé à consommer les ligneux augmente avec la taille du troupeau. Ceci met en évidence les limites de la notion de charge cumulée, qui selon les composantes (surface pâturée, durée de pâturage et nombre d'animaux) peuvent conduire à des prélèvements alimentaires différents. 